\title{
Impact and cost-effectiveness of a universal strategy to promote physical activity in primary care: population-based Cohort study and Markov model
}

\author{
Martin C. Gulliford · Judith Charlton • \\ Nawaraj Bhattarai · Christopher Charlton • \\ Caroline Rudisill
}

Received: 17 October 2012/Accepted: 26 March 2013/Published online: 10 April 2013

(C) The Author(s) 2013. This article is published with open access at Springerlink.com

\begin{abstract}
Background This study aimed to estimate the costeffectiveness of a universal strategy to promote physical activity in primary care.

Methods Data were analysed for a cohort of participants from the general practice research database. Empirical estimates informed a Markov model that included five long-term conditions (diabetes, coronary heart disease, stroke, colorectal cancer and depression). Simulations compared an intervention promoting physical activity in healthy adults with standard care. The intervention effect on physical activity was from a meta-analysis of randomised trials. The annual cost of intervention, in the base case, was one family practice consultation per participant year. The primary outcome was net health benefit in quality adjusted life years (QALYs).

Results A cohort of 262,704 healthy participants entered the model. Intervention was associated with an increase in life years lived free from physical disease. With 5 years intervention the increase was $52(95 \%$ interval -11 to $115)$ per 1,000 participants entering the model (probability increased $91.9 \%$ ); with 10 years intervention the increase was $102(42-164)$ per 1,000 (probability $99.7 \%$ ). Net
\end{abstract}

M. C. Gulliford $(\bowtie) \cdot$ J. Charlton · N. Bhattarai

Department of Primary Care and Public Health Sciences,

King's College London, Capital House,

42 Weston St, London SE1 3QD, UK

e-mail: martin.gulliford@kcl.ac.uk

C. Charlton

Centre for Multilevel Modelling, University of Bristol,

Bristol, UK

C. Rudisill

Department of Social Policy, London School of Economics

and Political Science, London, UK health benefits at a threshold of $£ 30,000$ per QALY were 3.2 ( -11.1 to 16.9$)$ QALYs per 1,000 participants with 5 years intervention (probability cost-effective $64.7 \%$ ) and $5.0(-9.5$ to 19.3$)$ with 10 years intervention (probability cost-effective $72.4 \%$ ).

Conclusions A universal strategy to promote physical activity in primary care has the potential to increase life years lived free from physical disease. There is only weak evidence that a universal intervention strategy might prove cost-effective.

Keywords Physical activity - Primary care $\cdot$ Markov model · Outcomes · Cost-effectiveness · Depression . Diabetes $\cdot$ Coronary heart disease $\cdot$ Stroke .

Colorectal cancer

JEL Classification I10 Health · General - D61 . Allocative efficiency

\section{Introduction}

Physical inactivity is one of the most important risk factors for chronic disease [1]. Epidemiological studies show that higher levels of physical activity are associated with lower frequency of diabetes, coronary heart disease, stroke, colorectal cancer and depression [1]. The promotion of physical activity has become a key global public health objective [2]. Current recommendations recognise that there is a "clear link between physical activity and chronic disease' [3] and advise that all adults should take at least $150 \mathrm{~min}$ of moderate physical activity per week with daily activity. Achieving this objective requires action through multiple sectors and at different levels [4]. This research considers the role of primary care services in promoting physical activity. 
Health services increasingly emphasise healthy ageing, aiming to prevent disease and reduce the impact of long-term conditions in later life [5]. Primary care services have a potentially important role to play in promoting physical activity. A recent meta-analysis of randomised trials found that brief interventions in primary care could result in one additional person achieving recommended physical activity levels for each 12 persons exposed to the intervention, with the effect being maintained over 12 months [6]. Williams [7] observed that 'brief exercise advice has a small effect on increasing physical activity... Such a small effect could be important if carried out on a large population of patients' [7].

The potential long-term effects of interventions to promote physical activity in primary care are not known. Existing reviews have included studies up to 2 years duration with behaviour change and physical fitness as outcomes [6]. Evidence that increased physical activity may reduce the incidence of diabetes is drawn from studies that included high risk individuals with impaired glucose tolerance or pre-diabetes [8]. The present research therefore aimed to evaluate the potential long term health outcomes and cost effectiveness of a universal strategy to promote physical activity in primary care. The research specifically aimed to determine whether a low-cost intervention with a limited intervention effect size, such as that evidenced by the recent meta-analysis on the effectiveness of such interventions [6], would prove cost-effective for implementation across the general population through primary health care services.

\section{Methods}

\section{Markov model structure}

A Markov model was employed to implement a cost-utility analysis of a universal strategy to promote physical activity in the general population registered in primary care, comparing a brief intervention to promote physical activity with 'standard care' in which there is no systematic approach to promote physical activity. A simplified diagram of the Markov model is shown in Fig. 1. The model structure was informed by previously reported research [9]. Healthy subjects, referred to as 'At Risk', may develop one of the disease states of interest, including Diabetes, Coronary Heart Disease, Stroke or Colorectal Cancer. Participants in one of these disease states may develop a second, third or fourth disease, giving 16 single- or multi-disease states, consistent with the frequent occurrence of multimorbidity as a driver of health care utilisation in primary care populations [10]. Participants in each state were allowed to progress to Depression, with each state divided into states representing 'Not Depressed' and 'Depressed'. Depression was associated with its own decrement in utility as well as its own rate of health care utilisation. Depression was included because it occurs frequently in chronic illness and is associated with higher health care costs for a given chronic illness [11]. There were therefore 32 states in the model that represented all potential combinations of the included diseases and depression. All states might lead to death. The perspective of the model is that of health care services and only health care costs were included. A lifetime time horizon was used.

\section{GPRD cohort}

Data to populate the model were derived from a large cohort of participants drawn from the general population registered with the general practice research database (GPRD) [12]. The GPRD includes electronic health records of participants registered with approximately $600 \mathrm{UK}$ family practices. GPRD data were used to estimate the incidence of each state included in the model; the mortality in each state; and the health care utilisation and costs associated with each state. The use of fully anonymised GPRD data was approved by the MHRA Independent Scientific Advisory Committee (Ref. 09-085).

The GPRD cohort was drawn from all family practices that were continuously contributing data to the GPRD between 1 January 2004 and 30 October 2010. Participants comprised a random sample of 299,912 registered patients, aged 30-100 years. Incidence and mortality rates were estimated, by 10 -year age group and sex. As colorectal cancer cases were less numerous, we made the assumptions that the incidence of colorectal cancer was the same in participants with and without cardiovascular comorbidity, and the incidence of cardiovascular comorbidity was the same in participants with and without colorectal cancer. Incidence and mortality rates were similar to those reported from GPRD previously [13-15]. The prevalence of depression was estimated for each state in the Model based on GPRD data [11]. In the Model, we assumed that depression was not associated with mortality at any given level of physical disease.

Health care utilisation was estimated for each state from GPRD records, including utilisation of primary care (family practice consultations, telephone consultations, home visits and emergency and out-of-hours consultations), secondary care (including hospital admissions, outpatient visits, day case visits and emergency visits) and prescriptions. The annual costs associated with each state were estimated by multiplying the health care utilisation associated with the state by the costs of each unit of health care, which were obtained from standard reference sources for 2010 [16] (Table 1). Prescription costs were obtained by linking the Multilex drug code for each prescription record in GPRD with the prescription cost [17]. The empirical mean (standard deviation) of participant level 


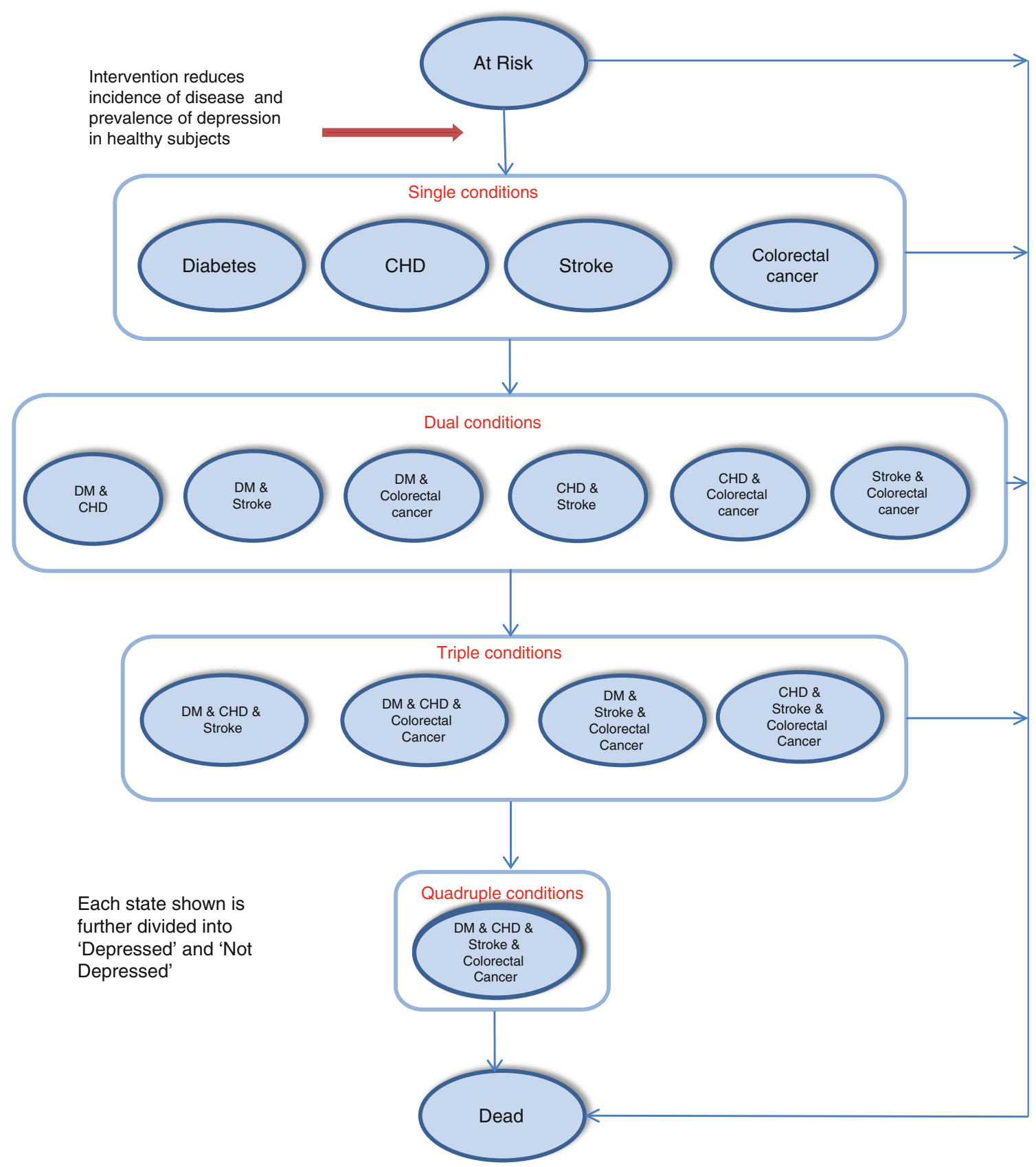

Fig. 1 Schematic diagram of Markov model. In order to simplify the diagram, the 32 incidence transitions and 16 mortality transitions are not represented in full. Each state is further divided into 'depressed' and 'not depressed'. CHD Coronary heart disease, DM type 2 diabetes mellitus

costs were estimated by age group, gender, depression status and condition. As the number of colorectal cancer cases was too small to subdivide into multi-disease states, health care utilisation was estimated for all colorectal cancer cases together.

\section{Model estimation}

The probabilistic Markov model was estimated by cohort simulation, implemented through a program written in $\mathrm{R}$ software [18]. After removing participants with prevalent disease, there were 262,704 healthy participants that entered the initial state of the Model, based on the distribution observed in GPRD, including $49 \%$ men. There were $37 \%$ aged <45 years and $42 \%$ were aged 45-64 years. All simulations were stratified by single year of age with the initial population aging by 1 year per cycle. Participants exited the model when they died or reached 100 years of age. The model was run for each sex separately. Outcomes and costs were compared for Intervention 
Table 1 Sources of data for model

\begin{tabular}{|c|c|c|c|c|}
\hline Data & Number/value & Source & Stratification & Comments \\
\hline Base population & 299,912 & GPRD & $\begin{array}{l}\text { Gender, 1-year age } \\
\text { group }\end{array}$ & $\begin{array}{l}\text { Participants with prevalent disease } \\
\text { were excluded. Age range } \\
30-100 \text { years }\end{array}$ \\
\hline Model states & 33 states & & $\begin{array}{l}\text { Stratified by gender, } \\
1 \text {-year age group. }\end{array}$ & $\begin{array}{l}\text { Includes At Risk, Diabetes, CHD, } \\
\text { Stroke, Colorectal cancer, } \\
\text { Depression and all combinations, } \\
\text { dead }\end{array}$ \\
\hline Incidence of states & 32 incidence rates & GPRD & $\begin{array}{l}\text { Gender, 10-year age } \\
\text { group }\end{array}$ & $\begin{array}{l}\text { Beta-binomial distribution used to } \\
\text { estimate transition probabilities; } \\
\text { incidence assumed independent of } \\
\text { depression; note that the same state } \\
\text { may be reached by more than one } \\
\text { transition (e.g. CHD in diabetes, } \\
\text { diabetes in CHD) }\end{array}$ \\
\hline Mortality of states & 16 mortality rates & GPRD & $\begin{array}{l}\text { Gender, 10-year age } \\
\text { group }\end{array}$ & $\begin{array}{l}\text { Beta-binomial distribution used to } \\
\text { estimate transition probabilities; } \\
\text { mortality assumed independent of } \\
\text { depression }\end{array}$ \\
\hline $\begin{array}{l}\text { Depression } \\
\text { prevalence }\end{array}$ & $\begin{array}{l}16 \text { depression } \\
\text { prevalence rates }\end{array}$ & GPRD & $\begin{array}{l}\text { Gender, 10-year age } \\
\text { group }\end{array}$ & $\begin{array}{l}\text { Beta-binomial distribution used to } \\
\text { estimate transition probabilities }\end{array}$ \\
\hline Health care utilization & $\begin{array}{l}\text { Utilisation rates } \\
\text { estimated for } 32 \text { states }\end{array}$ & GPRD & $\begin{array}{l}\text { Gender, 10-year age } \\
\text { group, depression } \\
\text { status }\end{array}$ & $\begin{array}{l}\text { Utilisation included primary care } \\
\text { consultations (including at general } \\
\text { practice, home, telephone and out of } \\
\text { hours or emergency), secondary care } \\
\text { (including inpatient, outpatient, day } \\
\text { case and emergency) and } \\
\text { prescription number and content }\end{array}$ \\
\hline \multicolumn{5}{|c|}{ Unit costs of health care utilization } \\
\hline \multicolumn{5}{|l|}{ Primary care } \\
\hline Consultation & $£ 35$ & PSSRU [16] & & $\begin{array}{l}\text { Gamma distribution used to sample } \\
\text { costs }\end{array}$ \\
\hline $\begin{array}{l}\text { Emergency/out of } \\
\text { hours } \\
\text { consultation }\end{array}$ & $£ 35$ & PSSRU [16] & & \\
\hline Home visit & $£ 117$ & PSSRU [16] & & \\
\hline $\begin{array}{l}\text { Telephone } \\
\text { consultation }\end{array}$ & $£ 21$ & PSSRU [16] & & \\
\hline $\begin{array}{l}\text { Prescription unit } \\
\text { costs }\end{array}$ & Variable & FDBE [16] & & $\begin{array}{l}\text { Unit price linked by Multilex code to } \\
\text { GPRD prescription. Single pack } \\
\text { price assumed }\end{array}$ \\
\hline \multicolumn{5}{|l|}{ Secondary care } \\
\hline Inpatient episodes & $£ 493$ & PSSRU [16] & & \\
\hline Outpatient visits & $£ 189$ & PSSRU [16] & & \\
\hline Day case visits & $£ 143$ & PSSRU [16] & & \\
\hline Emergency visits & $£ 110$ & PSSRU [16] & & \\
\hline Utility values & Utility decrement & & & \\
\hline Age 43 years & 0.828 & Sullivan et al. [19] & $\begin{array}{l}\text { Stratified by single year } \\
\text { of age }\end{array}$ & $\begin{array}{l}\text { Beta function employed to sample } \\
\text { utility values }\end{array}$ \\
\hline $\begin{array}{l}\text { Per year increase } \\
\text { in age }\end{array}$ & -0.00029 & & & \\
\hline Diabetes & -0.0621 & & & \\
\hline CHD & -0.0557 & & & \\
\hline Stroke & -0.1009 & & & \\
\hline Colorectal cancer & -0.0378 & & & \\
\hline Depression & -0.1302 & & & \\
\hline
\end{tabular}


Table 1 continued

\begin{tabular}{|c|c|c|c|c|}
\hline Data & Number/value & Source & Stratification & Comments \\
\hline $\begin{array}{l}\text { No. of chronic } \\
\text { conditions } 2\end{array}$ & -0.0615 & & & \\
\hline $\begin{array}{l}\text { No. of chronic } \\
\text { conditions } 3\end{array}$ & -0.0667 & & & \\
\hline $\begin{array}{l}\text { No. of chronic } \\
\text { conditions } 4\end{array}$ & -0.0433 & & & \\
\hline $\begin{array}{l}\text { No. of chronic } \\
\text { conditions } 5\end{array}$ & -0.0287 & & & \\
\hline
\end{tabular}

GPRD General practice research database, PSSRU Personal Social Services Research Unit, FDBE First DataBank Europe

and Standard Care over 70 annual cycles, this allowed the entire cohort to progress either to death or to reach age 100 and exit the model.

Annual transition probabilities for the model were obtained by sampling from the beta-binomial distribution, using GPRD data as inputs (Table 1). Utilities for each state were obtained from data published in a compendium of values [19] (Table 1). Utility values for each state were stratified by single year of age but were the same for men and women. Utility values were sampled from the beta distribution. The costs of each state were sampled from the gamma distribution with the mean value from GPRD, by 10-year age group, sex, condition and depression status, as the empirical input.

Total costs and quality adjusted life years (QALYs) were obtained by summing across the 70 cycles of the model included in each simulation. There were 2,000 simulations run for each of intervention or standard care scenarios. Results are expressed as rates per 1,000 healthy participants entering the model. Mean costs, and the $95 \%$ range, were obtained from the data for 2,000 simulations. Incremental costs and QALYs were obtained as the difference between intervention and standard care scenarios. Costs and QALYs were discounted using a rate of $3.5 \%$, but QALYs were also discounted at a rate of $1.5 \%$ as a sensitivity analysis. Incremental costs were plotted against incremental QALYs to present a cost-effectiveness ellipse. Net health benefits (NHB), at a threshold value of $£ 30,000$ per QALY, were calculated as the difference between the increment in QALYs and the increment in costs divided by the threshold value of cost per QALY. A cost-effectiveness acceptability curve was plotted using a range of threshold values. The model was implemented with a half cycle correction for the estimation of QALYs and costs.

\section{Intervention effects}

The intervention was assumed to modify only the incidence of disease in healthy participants At Risk. The effect of intervention was estimated as a potential impact fraction
(PIF), following Cobiac et al. [20]. The PIF provides a means of estimating the extent to which a change in risk factor exposure is associated with a proportionate decline in the likelihood of an individual developing a disease outcome of interest. The PIF was estimated from three sources of data: (1) the effect of brief interventions in primary care on physical activity levels. Orrow et al. [6] estimated that the number needed to treat for an additional sedentary subject to become active was approximately 12 with an odds ratio of 1.42 (95\% confidence interval 1.17-1.73) and an event rate in control participants of $26 \%$ (507/1924); (2) Data for the distribution of physical activity in the general population, by 10-year age group and sex, were obtained from the Health Survey for England 2008 [21]; (3) Relative risks associating inactivity, or insufficient activity, with the four study disease outcomes (diabetes, coronary heart disease, stroke and colorectal cancer) were obtained from the WHO study 'Comparative Quantification of Health Risks' [22]. Consistent with the WHO study we did not include a possible effect of intervention on depression prevalence because the evidence is inconsistent and disputed. The PIF was estimated as outlined by Cobiac et al. [20], with estimates being derived, in each cycle, for single years of age and sex based on the empirical estimates from the three data sources.

The intervention was modelled as being maintained for either 5 or 10 years. In the absence of evidence for the time course of intervention effects, the same estimates were used to model the intervention effect in each of the first five or ten cycles of the model as appropriate.

The cost of the intervention was modelled as a fixed cost per person year depending on their physical activity level. The population At Risk was divided into those that were physically active and those that were physically inactive or who took insufficient physical activity, based on the distribution observed in the Health Survey for England 2008. In the population that was not sufficiently physically active the intervention cost, in the base case, was modelled as being equivalent to the cost of one family practice consultation per person year (£35) [16]. In the population that 
was physically active, the cost of screening questions to evaluate physical activity levels was $20 \%$ of one family practice consultation per year. Orrow et al. reported that 'Most [brief physical activity interventions in primary care] included written materials and two or more sessions of advice or counselling on physical activity, delivered face to face' [6]. As sensitivity analyses, therefore, we also considered costs of intervention in inactive individuals equivalent to two family practice consultations per year (£70) and $20 \%$ of a family practice consultation per year (£7).

\section{Results}

The estimated values for intervention effects, derived from the estimated PIFs, are shown in Table 2. The figures are the mean, standard deviation and range of values for 2,000 simulations, with each value representing the mean across all ages in the first cycle of each simulation. An intervention effect of 0.95 indicates that the incidence of the condition of interest will, on average, be $5 \%$ lower with intervention.

There were 262,704 healthy participants, with the same age and gender distribution as in GPRD, who entered the model in each simulation (Table 3, Fig. 1). For an intervention lasting 5 years, there was an increase in life years lived without physical disease of 52.1 ( -10.9 to 115.3$)$ per 1,000 participants entering the model. The probability that life years free from disease was increased was $91.9 \%$. Figure 2 shows the time-course of changes in single- and multiple-morbidity following the start of intervention. As

Table 2 Estimated values for intervention effects derived from potential impact fractions (PIFs)

\begin{tabular}{lll}
\hline & Male & Female \\
\hline $\begin{array}{lll}\text { Diabetes mellitus } \\
\text { Mean (SD) }\end{array}$ & $0.966(0.010)$ & $0.967(0.010)$ \\
$\quad$ Range & $0.919-0.997$ & $0.934-0.998$ \\
Coronary heart disease & & \\
Mean (SD) & $0.949(0.015)$ & $0.951(0.015)$ \\
Range & $0.892-1.003$ & $0.905-1.001$ \\
Stroke & & \\
Mean (SD) & $0.968(0.010)$ & $0.969(0.010)$ \\
Range & $0.932-1.001$ & $0.930-1.001$ \\
Colorectal cancer & & $0.961(0.012)$ \\
Mean (SD) & $0.959(0.012)$ & $0.915-1.004$ \\
Range & $0.913-1.002$ & \\
\hline
\end{tabular}

Figures are the mean (SD) and range for 2,000 simulations for values in the first cycle of the model. Values may be interpreted as relative risks expected, single morbidities were reduced during the intervention period, but the reduction in single-morbidities persisted, while diminishing, following the end of intervention. There was greater than $95 \%$ probability that single morbidities were reduced from the second to the 11 th year following the start of intervention. A reduction in dual morbidities reached its maximum, approximately 20 years following the start of intervention, while a reduction in triple morbidity reached a maximum approximately 30 years following the start of intervention. There was an $87.6 \%$ probability that life years lived with single morbidities was reduced overall (Table 3). The equivalent figure for dual morbidities was $73.3 \%$; triple morbidities, $58.7 \%$; and quadruple morbidities, $49.6 \%$. Although the intervention was modelled to have no direct effect on depression prevalence, overall life years with depression tended to be reduced because of the empirical observation that depression prevalence was higher in individuals with morbidity.

When the intervention was maintained for 10 years, life years lived free from disease were increased by 102.3 per 1,000 participants entering the intervention (probability increased $99.7 \%$ ). Life years lived with single morbidities were reduced by 69.6 per 1,000 , probability $98.7 \%$; dual morbidities were reduced by 16.1 per 1,000 , probability, $88.9 \%$. There was a $69.8 \%$ probability that life years with triple morbidity were reduced and $76.6 \%$ probability that life years with depression were reduced. There was only weak evidence that total life years were increased after either 5 or 10 years intervention (Table 3).

Table 4 shows the changes in costs and QALYs associated with the intervention. With an intervention of 5 years duration, the discounted incremental costs of intervention were $£ 97,572$ per 1,000 participants entering intervention, with $86 \%$ of the cost attributable to intervention in participants who were inactive or insufficiently active. Approximately $14 \%$ of the cost of intervention was attributable to confirming the physical activity status of participants that were already active. The costs of nonintervention health care utilisation tended to be reduced through intervention by $-£ 16,818$ (probability reduced $63.7 \%$ ). Thus the overall total incremental costs under intervention were $£ 80,744$ (probability increased $95.5 \%$ ).

The discounted incremental QALYs associated with intervention were 5.9 per 1,000 participants entering intervention (Table 4). The probability that QALYs were increased among the population was $75.7 \%$. Net Health Benefits associated with intervention were 3.2 QALYs per 1,000 participants entering intervention. The probability that the intervention would be cost-effective at a threshold of $£ 30,000$ per QALY was $64.7 \%$.

For an intervention maintained for 10 years the overall incremental total costs were $£ 144,469$ per 1,000 . The 
Table 3 Health outcomes and cost-effectiveness of a physical activity intervention in a population of 262,704 healthy participants

\begin{tabular}{|c|c|c|c|c|}
\hline & \multicolumn{4}{|l|}{ Intervention duration } \\
\hline & \multicolumn{2}{|l|}{5 Years } & \multicolumn{2}{|l|}{10 Years } \\
\hline & $\begin{array}{l}\text { Difference } \\
\text { (intervention-standard care) }\end{array}$ & $\begin{array}{l}\text { Probability } \\
(\%)\end{array}$ & $\begin{array}{l}\text { Difference } \\
\text { (intervention-standard care) }\end{array}$ & $\begin{array}{l}\text { Probability } \\
(\%)\end{array}$ \\
\hline Number entering intervention & 262,704 & & 262,704 & \\
\hline Life years lived without disease (per 1,000$)^{\mathrm{a}}$ & $52.1(-10.9$ to 115.3$)$ & $91.9^{\mathrm{b}}$ & $102.3(42.3$ to 163.7$)$ & $99.7^{\mathrm{b}}$ \\
\hline \multicolumn{5}{|c|}{ Life years lived with physical morbidity $(\text { per } 1,000)^{\mathrm{a}}$} \\
\hline Single condition & $-34.1(-82.3$ to 13.7$)$ & $87.6^{\mathrm{c}}$ & $-69.6(-119.3$ to -21.6$)$ & $98.7^{\mathrm{c}}$ \\
\hline Dual conditions & $-8.3(-29.1$ to 12.6$)$ & $73.3^{\mathrm{c}}$ & $-16.1(-38.8$ to 5.7$)$ & $88.9^{\mathrm{c}}$ \\
\hline Triple conditions & $-0.96(-8.0$ to 5.7$)$ & $58.7^{\mathrm{c}}$ & $-2.0(-9.0$ to 5.0$)$ & $69.8^{\mathrm{c}}$ \\
\hline Quadruple conditions & $-0.01(-1.4$ to 1.4$)$ & $49.6^{\mathrm{c}}$ & $-0.1(-1.5$ to 1.3$)$ & $53.6^{\mathrm{c}}$ \\
\hline Life years lived with depression (per 1,000$)^{\mathrm{a}}$ & $-2.8(-17.9$ to 11.8$)$ & $61.9^{\mathrm{c}}$ & $-6.4(-20.4$ to 7.9$)$ & $76.6^{\mathrm{c}}$ \\
\hline Total life years (per 1,000$)^{\mathrm{a}}$ & $8.9(-35.6$ to 52.3$)$ & $62.7^{\mathrm{b}}$ & $14.6(-29.2$ to 59.3$)$ & $71.1^{\mathrm{b}}$ \\
\hline
\end{tabular}

Figures represent mean and $95 \%$ range of 2,000 simulations

${ }^{a}$ Per 1,000 healthy participants entering model

b Probability measure is higher with intervention

${ }^{c}$ Probability measure is lower with intervention

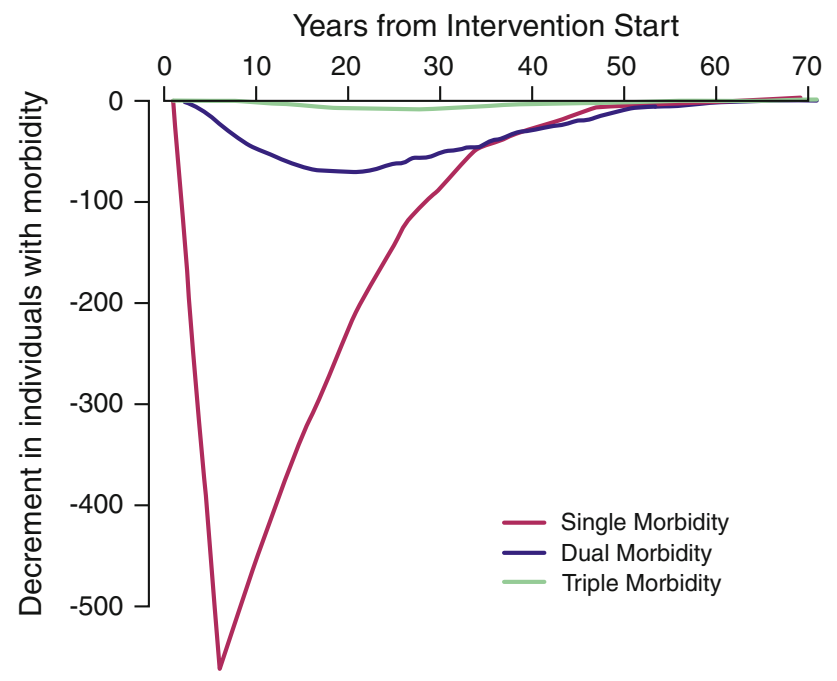

Fig. 2 Changes over time in levels of single and multiple morbidity following an intervention of 5 years duration. Data represent the mean difference between intervention and standard care by year (color figure online)

incremental QALYs associated with intervention were 14.9 per 1,000 (probability increased $85.1 \%$ ). The Net Health Benefits at a threshold of $£ 30,000$ per QALY were 5.0 per 1,000 . The probability of the intervention being costeffective at the same threshold was $72.4 \%$.

Figure 3 presents a cost-effectiveness plane, in which incremental costs are plotted against incremental QALYs for each of the 2,000 simulations. Figure 3 also presents a cost-effectiveness acceptability curve, in which the probability of the intervention being cost-effective was estimated at different thresholds values of cost per QALY. An intervention continuing for either 5 or 10 years did not achieve more than an $80 \%$ probability of being costeffective, except at longer intervention duration and high threshold values of cost per QALY, because there were appreciable numbers of simulations in which intervention was associated with no increase in QALYs.

\section{Sensitivity analyses}

Sensitivity analyses were implemented to explore the effects of varying the unit costs of intervention and varying the discount rate. As expected, increasing the unit costs of intervention necessarily made the intervention less costeffective. If the cost of a 5-year intervention was equivalent to two family practice consultations per year, then net health benefits were approximately zero $(-0.06,-14.3$ to 13.6 QALYs per 1,000). However, reducing the costs of intervention had only a modest effect because the proportion of simulations in which incremental QALYs were zero or lower set a limit to the potential increase in cost-effectiveness. If the cost of a 5-year intervention was equivalent to $20 \%$ of one family practice consultation per year, then net health benefits were 5.8 ( -8.5 to 19.5 QALYs per 1,000, probability cost effective $75.1 \%$ ). When QALYs were discounted at $1.5 \%$ rather than $3.5 \%$, there was only a small difference in the probability of the intervention proving cost effective at 5 years (probability $66.0 \%$ ) or 10 years $(76.8 \%$ ), although estimated mean net health benefits were greater, being 6.0 QALYs per 1,000 for an intervention lasting 5 years and 10.1 QALYs per 1,000 for an intervention lasting 10 years. 
Table 4 Health outcomes and cost-utility of a physical activity intervention in a population of 262,704 healthy participants

\begin{tabular}{|c|c|c|c|c|}
\hline & \multicolumn{4}{|l|}{ Intervention duration } \\
\hline & \multicolumn{2}{|l|}{5 years } & \multicolumn{2}{|l|}{10 years } \\
\hline & $\begin{array}{l}\text { Difference (intervention- } \\
\text { standard care) }\end{array}$ & $\begin{array}{l}\text { Probability } \\
(\%)\end{array}$ & $\begin{array}{l}\text { Difference (intervention- } \\
\text { standard care) }\end{array}$ & $\begin{array}{l}\text { Probability } \\
(\%)\end{array}$ \\
\hline Number entering intervention & 262,704 & & 262,704 & \\
\hline Intervention costs in physically active ( $£$ per 1,000$)$ & $13,995(13,989$ to 14,001$)$ & 100.0 & $24,018(24,003$ to 24,033$)$ & 100.0 \\
\hline Intervention costs in physically inactive ( $£$ per 1,000$)$ & $83,567(83,531$ to 83,601$)$ & 100.0 & $\begin{array}{l}152,210(152,110 \text { to } \\
152,306)\end{array}$ & 100.0 \\
\hline Total intervention costs $(£$ per 1,000$)$ & $97,572(97,521$ to 97,602$)$ & 100.0 & $\begin{array}{l}176,228(176,113 \text { to } \\
176,340)\end{array}$ & 100.0 \\
\hline $\begin{array}{l}\text { Incremental costs of non-intervention health care } \\
\text { utilisation ( } £ \text { per } 1,000)\end{array}$ & $\begin{array}{l}-16,818(-94,269 \text { to } \\
60,747)\end{array}$ & $63.7^{\mathrm{b}}$ & $\begin{array}{l}-31,760(-109,077 \text { to } \\
47,599)\end{array}$ & $74.3^{\mathrm{b}}$ \\
\hline Incremental total costs $(£ \text { per } 1,000)^{\mathrm{a}}$ & $80,744(3,326$ to 158,251$)$ & 95.5 & $144,469(67,103$ to 223,843$)$ & 99.9 \\
\hline Incremental QALYs (discounted $3.5 \%$ ) (per 1,000) & $5.9(-8.2$ to 19.7$)$ & 75.7 & $9.8(-4.6$ to 23.6$)$ & 87.3 \\
\hline Incremental QALYs (discounted $1.5 \%$ ) (per 1,000) & $8.6(-14.7$ to 32.4$)$ & 72.7 & $14.9(-8.7$ to 38.5$)$ & 85.1 \\
\hline Net health benefits (QALYs per 1,000 ) & $3.2(-11.1$ to 16.9$)$ & 64.7 & $5.0(-9.5$ to 19.3$)$ & 72.4 \\
\hline Probability cost effective at $£ 30,000$ per QALY (\%) & 64.7 & & 72.4 & \\
\hline
\end{tabular}

Figures represent mean and $95 \%$ range of 2,000 simulations. $Q A L Y$ Quality-adjusted life year, CHD coronary heart disease

${ }^{a}$ Per 1,000 healthy participants entering model

b Probability reduced

\section{Discussion}

What this study shows

This study modelled the health outcomes of a universal intervention, aimed at all healthy adults, to promote physical activity in primary care. The study employed an empirical population of adults registered with UK family practices; the size of the population at risk was equivalent in size to that of a small town or a primary care organisation. The intervention effect was derived from a meta-analysis of randomised controlled trials, based on the distribution of physical activity observed in a representative population sample in England. The results show that an intervention with only a small effect on the risk of disease may yield appreciable health benefits including an increase in life years lived free from physical disease and a reduction in life years lived with either single or multiple comorbidity. An important finding from this study is that interventions, or intervention effects in terms of behavioural changes resulting from intervention, must be maintained over prolonged periods of time in order for substantial health benefits to accumulate. This long time scale for the emergence of health benefits presents a challenge in allocating primary care resources to delayed rather than immediate benefits. The present results suggest that a brief intervention in primary care represents a costly way of achieving population-wide outcomes. Even when the intervention is delivered at very low unit cost, there is only weak evidence that the intervention could have acceptable cost-effectiveness. These results therefore offer only limited support to continued investigation of a universal intervention as part of a standard family practice visit. Future research should evaluate whether interventions targeted at high-risk individuals may be more suitable for utilisation in primary care, with population strategies being delivered through multi-sectoral interventions.

What other studies show

Hillsdon's [23] review of interventions to promote physical activity included studies published up to 2004. Of the 29 studies, 15 were set in primary care, including a range of intervention and follow-up methods. The overall increase in physical activity through intervention amounted to 0.28 standard deviations (SD) for a physical activity measure, with a 0.52 SD increase in physical fitness in 11 studies. This review provides evidence that interventions in primary care to promote physical activity may be effective, at least in the short term. These conclusions are supported by more recent systematic reviews [6, 24]. However, individual level behavioural interventions to promote physical activity may be more costly that we have estimated for this study. Muller-Reimenschneider found a value of Euro 800 per year [25]. Recent studies suggest that community-wide or environmental interventions aimed at increasing use of leisure facilities [26] or promoting active travel [27] may have more acceptable cost-effectiveness. 

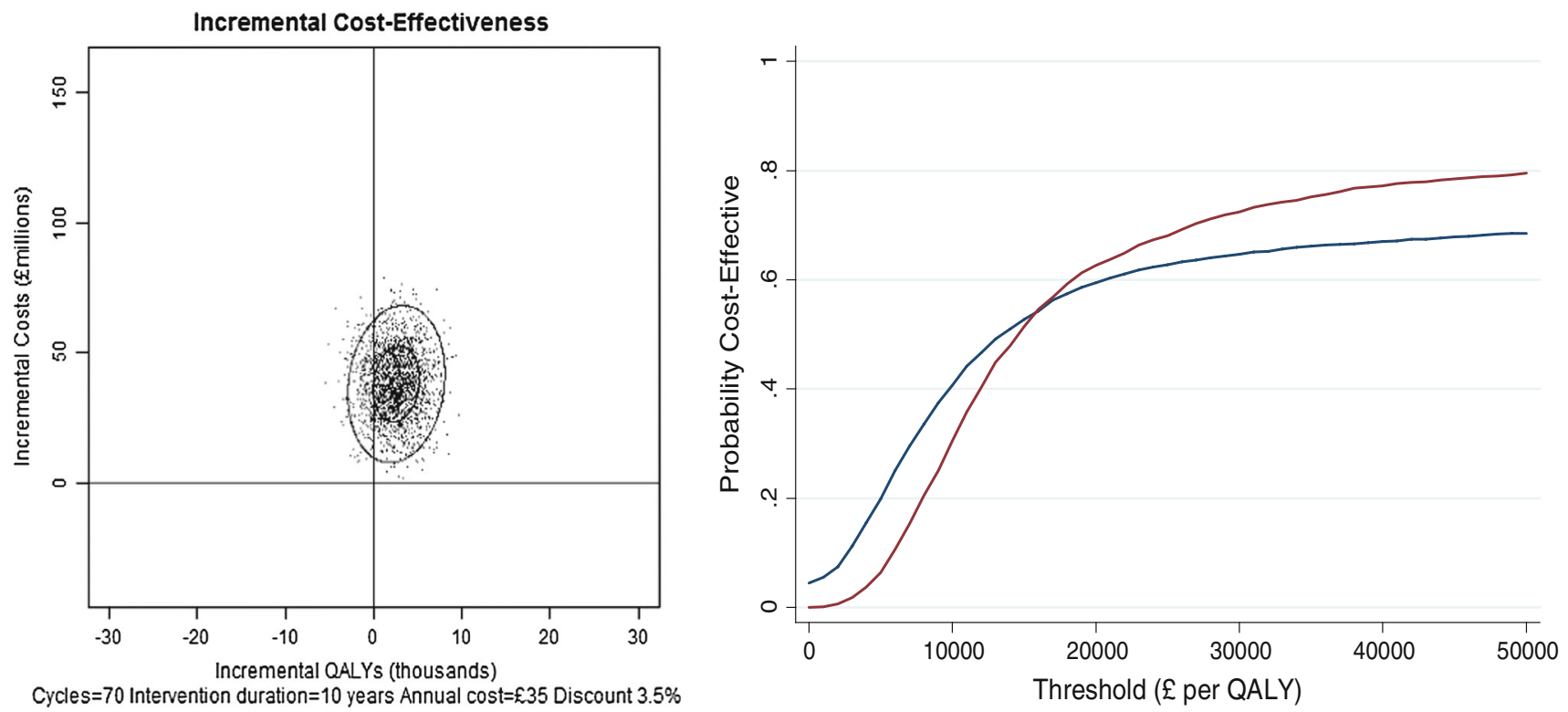

Fig. 3 Left panel Cost-effectiveness plane showing results of 2,000 simulations with 10 years' intervention. Outer ellipse encompasses $95 \%$ of simulations. Right panel Cost-effectiveness acceptability curves for 5 (blue) and 10 (red) years intervention (color figure online)

Strengths and limitations of this study

This research was grounded in data from a very large cohort of participants from primary care, which provided strong empirical evidence to construct the model. Nevertheless, some multi-disease states were less frequent, leading to imprecise estimates. There were numerous estimates for incidence, mortality, prevalence of depression, as well as health care utilisation contributing to stochastic error in the Model inputs and consequently to uncertainty in the Model outputs. Utility values were drawn from a secondary source because it was not feasible to obtain primary data for multiple disease states within the context of this study. The QALY estimates in this source rely on a US-based survey. While our study is UK-based, this secondary data source provided consistent estimates covering the number of disease states in this research. Uncertainty in utility estimates was incorporated into the Model through the probabilistic approach. Sensitivity analyses were implemented to study the effect of varying key parameters. We did not set an upper age limit to eligibility for intervention because physical activity is beneficial even in old age [28]. The model included only a limited range of health conditions and it is possible that there are wider health benefits of intervention that were not included. The model assumed that mortality reductions would be achieved only through the conditions of interest and not by reductions in mortality from other causes [29]. The model did not include secular trends in the measures of interest because the direction of future trends is unknown.

We acknowledge that true long-term intervention effects are not known and the model requires an important assumption that short-term effects must be maintained if the intervention is continued. We used results from a metaanalysis of randomised trials to provide an estimate of the intervention effect. However, most of the included studies used self-reported measures of physical activity and a similar effect has not been demonstrated employing objective measures. In a probabilistic framework, we used the standard error to model random error in the point estimate of the intervention effect. The intervention time course is also unknown and we did not model scenarios in which the effect of intervention might outlast the intervention itself. We also did not assume any social multiplier effects in our modelling where the impact of one person taking on more physical exercise might influence others' around him therefore possibly underestimating intervention effect size. Intervention effects were not allowed to vary in different population groups but we intend to study this further in future studies. We modelled several different estimates for intervention costs. It is clear that an intervention of very low cost has only a limited probability of proving cost-effective, with a more costly intervention yielding little or no net benefit. However, more complex scenarios could be envisaged in which the major costs may be incurred at the start, with lower maintenance costs. The model included only health care costs; conclusions might differ appreciably if other costs and productivity changes were to be included. In particular, the opportunity costs of leisure-time physical activity are important [30]. The data were obtained from primary care records and utilisation of secondary care may also have been underestimated as we could not follow patient use of secondary care resources 
beyond referral and admission. We used the average of costs over all stages of a disease but this is a simplification because, in reality, costs may be higher at the start of the illness, or at periods closer to death. We caution that most estimates included in the Model derived from the British primary health care system. Costs and outcomes may be different in other countries and settings where resource use, the costs of care, and levels of physical activity and barriers to physical activity may be different.

\section{Conclusions}

The results contribute new information towards understanding the potential for a universal strategy for physical activity promotion in primary care. Firstly, an important increase in time lived free from physical disease, and a reduction in the time lived with single or multiple morbidity, may result from even a modest increase in physical activity levels. Secondly, intervention effects must be maintained over a prolonged period of time in order for substantial health benefits to be realised, though these may continue to accumulate after the end of the intervention. Individuals receiving the intervention must effectively change lifelong behaviours in order to benefit. Thirdly, even when interventions can be delivered over the longterm at low annual cost, such as the cost of an additional family practice consultation each year, there is only weak evidence that the intervention might have acceptable costeffectiveness when employed in a universal strategy. The present results emphasise that physical activity is a determinant of health important to primary care professionals, but also show that implementation of a universal strategy within primary care faces several challenges. While the results indicate some potential for a universal strategy, an alternative approach, which will be evaluated in future research, is the delivery of a selective or targeted strategy to focus intervention efforts on those at higher risk of disease.

Acknowledgments The authors thank Professor Alistair McGuire for advice. This study is based in part on data from the Full Feature General Practice Research Database obtained under licence from the UK Medicines and Healthcare Products Regulatory Agency. However, the interpretation and conclusions contained in this study are those of the authors alone. This study was supported by the UK National Prevention Research Initiative (http://www.npri.org.uk) whose funding partners include the Alzheimer's Research Trust; Alzheimer's Society; Biotechnology and Biological Sciences Research Council; British Heart Foundation; Cancer Research UK; Chief Scientist Office, Scottish Government Health Directorate; Department of Health; Diabetes UK; Economic and Social Research Council; Engineering and Physical Sciences Research Council; Health \& Social Care Research \& Development Office for Northern Ireland; Medical Research Council; The Stroke Association; Welsh Assembly Government; and World Cancer Research Fund. The authors were also supported by the National Institute for Health Research (NIHR) Biomedical Research Centre at Guy's and St Thomas' NHS Foundation Trust and King's College London. The views expressed are those of the author(s) and not necessarily those of the NHS, the NIHR or the Department of Health. MG and CR also receive support from the Wellcome Trust; MG receives support from the Guy's and St Thomas' Charity. The funders played no role in the design, analysis or reporting of the study.

\section{Conflict of interest None.}

Ethical standard The use of fully anonymised GPRD data was approved by the MHRA Independent Scientific Advisory Committee (Ref. 09-085).

Open Access This article is distributed under the terms of the Creative Commons Attribution License which permits any use, distribution, and reproduction in any medium, provided the original author(s) and the source are credited.

\section{References}

1. Lee, I.M., Shiroma, E.J., Lobelo, F., Puska, P., Blair, S.N., Katzmarzyk, P.T.: Effect of physical inactivity on major non-communicable diseases worldwide: an analysis of burden of disease and life expectancy. Lancet 380, 219-229 (2012)

2. World Health Organization: Global strategy on diet, physical activity and health. World Health Organization, Geneva (2004)

3. Department of Health: UK physical activity guidelines. Department of Health, London (2011)

4. Heath, G.W., Parra, D.C., Sarmiento, O.L., Andersen, L.B., Owen, N., Goenka, S., et al.: Evidence-based intervention in physical activity: lessons from around the world. Lancet 380, 272-281 (2012)

5. Wanless, D.: Securing good health for the whole population. Final report. HMSO, London (2004)

6. Orrow, G., Kinmonth, A.-L., Sanderson, S., Sutton, S.: Effectiveness of physical activity promotion based in primary care: systematic review and meta-analysis of randomised controlled trials. BMJ 344, e1389 (2012). doi:10.1136/bmj.e1389

7. Williams, N.H.: Promoting physical activity in primary care. BMJ 343, d6615 (2011). doi:10.1136/bmj.d6615

8. Gillies, C.L., Abrams, K.R., Lambert, P.C., Cooper, N.J., Sutton, A.J., Hsu, R.T., et al.: Pharmacological and lifestyle interventions to prevent or delay type 2 diabetes in people with impaired glucose tolerance: systematic review and meta-analysis. BMJ 334, 299 (2007)

9. Herman, W.H., Hoerger, T.J., Brandle, M., Hicks, K., Sorensen, S., Zhang, P., Hamman, R.F., Ackermann, R.T., Engelgau, M.M., Ratner, R.E.: The cost-effectiveness of lifestyle modification or metformin in preventing type 2 diabetes in adults with impaired glucose tolerance. Ann. Intern. Med. 142, 323-332 (2005)

10. Barnett, K., Mercer, S.W., Norbury, M., Watt, G., Wyke, S., Guthrie, B.: Epidemiology of multimorbidity and implications for health care, research, and medical education: a cross-sectional study. Lancet 380(9836), 37-43 (2012)

11. Bhattarai, N., Charlton, J., Rudisill, C., Gulliford, M.C.: Prevalence of depression and utilization of health care in single and multiple morbidity: a population-based cohort study. Psychol. Med. Nov 1, 1-9 (2012). doi:10.1017/S0033291712002498

12. Herrett, E., Thomas, S.L., Schoonen, W.M., Smeeth, L., Hall, A.J.: Validation and validity of diagnoses in the general practice research database: a systematic review. Br. J. Clin. Pharmacol. 69, 4-14 (2010) 
13. Charlton, J., Latinovic, R., Gulliford, M.C.: Explaining the decline in early mortality in men and women with type 2 diabetes. Population-based cohort study. Diabetes Care 31, 1761-1766 (2008)

14. Gulliford, M.C., Charlton, J., Ashworth, M., Rudd, A.G., Toschke, A.M.: Selection of medical diagnostic codes for analysis of electronic patient records. Application to stroke in a primary care database. PLoS ONE 4, e7168 (2009)

15. Bhattarai, N., Charlton, J., Rudisill, C., Gulliford, M.C.: Coding, recording and incidence of different forms of coronary heart disease in primary care. PLoS ONE 7, e29776 (2012)

16. Personal Social Services Research Unit: Unit costs of health and social care. In: Curtis, L. (ed.) Personal Social Services Research Unit. University of Kent, Canterbury (2010)

17. First Data Bank Europe: FDBE Multilex Drug Data File. First Data Bank Europe, Exeter (2011)

18. R Development Core Team. R: A language and environment for statistical computing. R Foundation for Statistical Computing, Vienna, Austria. ISBN 3-900051-07-0. http://www.R-project.org/ (2012)

19. Sullivan, P.W., Slejko, J.F., Sculpher, M.J., Ghushchyan, V.: Catalogue of EQ-5D scores for the United Kingdom. Med. Decis. Making 31, 800-804 (2011)

20. Cobiac, L.J., Vos, T., Barendregt, J.J.: Cost-effectiveness of interventions to promote physical activity: a modelling study. PLoS Med 6, e1000110 (2009)

21. NHS Information Centre. Health survey for England 2008 trend tables. NHS Information Centre, Leeds UK, (2009). http://www. ic.nhs.uk/pubs/hse08trends. Accessed 13 September 2012

22. World Health Organization. Comparative Quantification of Health Risks. World Health Organization, Geneva (2004). http://www.who.int/healthinfo/global_burden_disease/cra/en/. Accessed 13 September 2012
23. Hillsdon, M., Foster, C., Thorogood, M.: Interventions for promoting physical activity. Cochrane Database Syst. Rev. 1, CD003180 (2005)

24. Conn, V.S., Hafdahl, A.R., Mehr, D.R.: Interventions to increase physical activity among healthy adults: meta-analysis of outcomes. Am. J. Public Health 101, 751-758 (2011)

25. Müller-Riemenschneider, F., Reinhold, T., Willich, S.N.: Costeffectiveness of interventions promoting physical activity. Br. J. Sports Med. 43, 70-76 (2009)

26. Frew, E.J., Bhatti, M., Win, K., Sitch, A., Lyon, A., Pallan, M., et al.: Cost-effectiveness of a community-based physical activity programme for adults (Be Active) in the UK: an economic analysis within a natural experiment. Br. J. Sports. Med. (2012). doi:10.1136/bjsports-2012-091202

27. Jarrett, J., Woodcock, J., Griffiths, U.K., Chalabi, Z., Edwards, P., Roberts, I., et al.: Effect of increasing active travel in urban England and Wales on costs to the National Health Service. Lancet 379, 2198-2205 (2012)

28. Xue, Q.-L., Bandeen-Roche, K., Mielenz, T.J., Seplaki, C.L., Szanton, S.L., Thorpe, R.J., et al.: Patterns of 12-year change in physical activity levels in community-dwelling older women: can modest levels of physical activity help older women live longer? Am. J. Epidemiol. 176, 534-543 (2012)

29. Byberg, L., Melhus, H., Gedeborg, R., Sundstrom, J., Ahlbom, A., Zethelius, B., Berglund, L.G., Wolk, A., Michaelsson, K.: Total mortality after changes in leisure time physical activity in 50 year old men: 35 year follow-up of population based cohort. BMJ 338, b688 (2009)

30. Hagberg, L.A., Lindholm, L.: Measuring the time costs of exercise: a proposed measuring method and a pilot study. Cost Eff. Resour. Alloc. 8, 9 (2010) 